\title{
Glycaemic Index of Sri Lankan Meals
}

\author{
S Pirasath ${ }^{*}$, Balakumar B and Arasaratnam V \\ Department of Biochemistry, Faculty of Medicine, University of Jaffna, Sri Lanka
}

*Corresponding author: Selladurai Pirasath, Demonstrator, Department of Biochemistry, Faculty of Medicine, University of Jaffna, Sri Lanka, Tel: 0775122995; E-mail: selladuraipirasath81@gmail.com

Received date: Dec 07, 2014, Accepted date: Feb 18, 2015, Publication date: Feb 23, 2015

Copyright: (C) 2015 Pirasath S, et al. This is an open-access article distributed under the terms of the Creative Commons Attribution License, which permits unrestricted use, distribution, and reproduction in any medium, provided the original author and source are credited.

\begin{abstract}
Glycemic Index (GI) is the measure of increase in blood glucose level after intake of food rich in carbohydrate related to glucose. There are many research projects have been carried out in several countries. There were no studies conducted for analyzing Gl of Northern traditional food items in Sri Lanka. This study was aimed to determine the GI values of our traditional foods alone and mixed meals. When dietary advices are given to diabetic and coronary heart disease patients, not only the basic foods have to be considered but also the slide dishes to be consumed. Consumption of food containing fiber diet will significantly reduce the rise in blood sugar level. However recommendation of the foods should be made after analyzing the glycemic index, glycemic load and energy contents of the foods. Lower Gl diets are better choices for the diabetes and coronary heart disease patients. Further studies have to be carried out on the prediabetes and diabetes. This study will be useful to Physicians and public to decide on the consumption of fruits particularly by the diabetic and coronary heart disease patients in Sri Lanka.
\end{abstract}

Keywords: Blood glucose; Meals; Coronary heart disease; Carbohydrates; Diabetics

\section{Introduction}

Glycemic Index (GI) is the measure of increase in blood glucose level after intake of food rich in carbohydrate related to glucose. i.e. GI of food represents its blood-glucose raising potential [1]. It is a ranking system for carbohydrates based on their effect on blood glucose levels [2]. The concept was invented by Dr. David, J. Jenkins et al. in 1981 at the University of Toronto [3]. Glycemic Index is defined as "the incremental area under the blood glucose response curve of $75 \mathrm{~g}$ carbohydrate portion of a food Expressed as a percent of response to same amount of carbohydrate from a standard food taken by same subject" [1].

It ranks foods on a scale from $0-100$, according to their actual effect on blood glucose level [4]

On GI scale, glucose is taken as 100 , because it causes greatest and most rapid rise in blood glucose. All other foods related in comparison to glucose. Foods with an index number of 70 (or) more are considered to be of high GI, with index number between $55-70$ as medium GI, and 55 (or) less as low GI [5]. Low GI diets help people to lose and control body weight [6], improve diabetic control and heart disease [7], increase body sensitivity to insulin [8], reduce blood glucose level [9] and prolong physical endurance [10].

\section{Sri Lankan Meals}

The different varieties of rice (Oryza sativa) such as (white rice ('Bg11-11'), raw brown rice ('At- 402') and parboiled rice ('Mottaikarupan') and raw mottaiarupan rice were main lunch time meals. 'Pittu', String hoppers', 'Thosai', 'Idly' are mainly consumed as breakfast/dinner meals. 'Pittu' are usually prepared from wheat flour, rice flour, 'atta' flour (whole wheat flour) and 'kurakkan' (Eleucine coracana). These meals are eaten with either green leaf curry (Amaranthus sp.) or soya meat gram gravy or 'Sambol' or 'Sampar' made of ravae vegetables such as tomatoes, carrot, drum strict, bringoles and yellow dhal. Manihot esculenta (boiled cassava) and legumes like Vigna radiata (boiled green gram) and Cicer arietinum (boiled chick pea), bakery products (bread, normal bun, butter cake, hard bun and rusk) are also consumed as snack meals. The fruits like different varieties of plantain (Musa spp) Tamil-'Kathali' (Sinhala'Embul'), Tamil-'Kappal' (Sinhala-'Kolikuttu') and Tamil-'Itharai' (Sinhala-'Poo kesel'), jack fruit and papaya are consumed. All foods were analyzed for their total sugar [11], total protein [11], moisture [11], and soluble dietary fiber [12], insoluble dietary fiber [12], and total dietary fiber contents [12]. The GI values of popular traditional meals alone and mixed meals in Northern Sri Lanka were determined in Jaffna $[13,14]$. These results will be useful to Physicians and public to decide on the consumption of meals particularly by the diabetic and coronary heart disease patients in Sri Lanka.

\section{Glycemic Index Values of Sri Lankan Meals}

\section{Glycemic index of different varieties of rice [15-21]}

The glycemic index (GI) values of cooked white rice, brown rice and parboiled rice were $66.61( \pm 9.86), 60.24( \pm 8.16)$ and $55.97( \pm 6.01)$ $\%$ respectively (Table 1$)$. When fiber contents of the three cooked rice varieties were considered the cooked parboiled rice contained more soluble dietary fibers $(0.42 \%)$, insoluble dietary fibers $(1.88 \%)$ and total dietary fibers $(2.3 \%)$, than the cooked brown rice $(0.21,1.88$ and $2.09 \%$ ) and cooked white rice (trace, 1.21 and $1.21 \%$ ). The available carbohydrate in the foods for absorption might be made unavailable due to its soluble dietary fibers (SDF), insoluble dietary fibers (IDF) and total dietary fibers (TDF) contents. The monosaccharaides released by the hydrolysis and available for absorption might be made unavailable. This could be due to the tendency of the fibers to absorb sugars and absorbed sugar released slowly. A soluble fiber slows down 
Page 2 of 6

the digestion of starches and absorption of the glucose in to blood stream. The total dietary fiber content of cooked parboiled rice was higher than that of the other cooked rice. When the insoluble dietary fiber is considered, the cooked parboiled rice contained same amount $(1.88 \%)$ and the cooked white rice contained lower (1.21\%) than other varieties. However the total dietary fiber contents of cooked parboiled rice and brown rice varieties were closer to each other. Thus the parboiled rice variety is a better choice for the diabetics and coronary heart disease patients [15].

\section{Food items prepared from rice flour [15-21]}

The mean glycemic index values of 'Pittu' and 'string hopper' were $43.74( \pm 9.09)$ and $50.01( \pm 7.06) \%$ respectively (Table 1$)$. When the fiber content of 'pittu' and string hopper were considered 'pittu' contained more soluble dietary fibers than $(0.45 \%)$, insoluble dietary fiber $(1.56 \%)$ and total dietary fiber $(2.01 \%)$ and string hopper contained soluble dietary fibers $0.43 \%$, insoluble dietary fiber $1.45 \%$ and total dietary fiber $1.88 \%$. The total dietary fiber of 'pittu' was higher than that of string hopper. 'piitu' and string hoppers are made out of roasted rice flour and steamed wheat flour. When the rice flour is roasted heat might have initiated the Mailard reaction and caramelization. With steaming the starch exposed to moist heat may undergo gelatinization and subsequently they may have retrograded causing a lowering effect on glycemic index. This might be the reason for the lower glycemic index values for 'pittu' and string hoppers when compared with cooked rice.

\section{Glycemic Index values of some tubers and legumes [15-21]}

The glycemic index (GI) values of cassava (Manihot esculenta), potato (Solanum tuberosum, Nuwara Elia), boiled green gram (Vigna radiata) and chick pea (Cicer arietinum) were determined (Table 1).

When boiled potato or cassava, which contained $75 \mathrm{~g}$ digestible carbohydrate, was administered to the volunteers the peak blood glucose level was obtained at $30 \mathrm{~min}$. The mean glycemic index values of potato and cassava were $65.2( \pm 6.56)$ and $78.7( \pm 7.3 \%)$. When the fiber contents of boiled potato and cassava are considered, the soluble dietary fiber $(0.48 \%, 0.47 \%)$, insoluble dietary fiber $(1.21 \%, 2.18)$ and total dietary fiber $(1.69 \%, 2.65)$ respectively. the mean glycemic response to boiled potato and boiled cassava were $40.8( \pm 4.11)$ and 49.3 ( \pm 4.57$) \mathrm{mg}$ dl-1 respectively. These values could not be due to the effect of soluble dietary fiber or insoluble dietary fiber in these two food items [15]. Because the boiled potato and cassava contained almost same amount of SDF and the boiled cassava contained higher IDF than boiled potato. Hence the fiber content did not affect the glycemic response of boiled potato and boiled cassava. Cooking also has shown to exert a differential effect on GI of a carbohydrate - rich food, particularly one that is high in starch. In the boiled and cooled potato the processing could have formed the resistant starch. Thus the variation in the glycemic index of boiled potato from boiled cassava could be due to more resistant starch formation in during boiling and cooling of potato and cassava. Thus cassava is a high GI diet.

When boiled green gram or chickpea, which contained $75 \mathrm{~g}$ digestible carbohydrate, was administered to the volunteers the peak blood glucose level was obtained at $60 \mathrm{~min}$. The mean glycemic index values of boiled green gram and boiled chickpea were $31.4( \pm 6.96)$ and $33.3( \pm 6.23 \%)$. When the fiber contents of boiled green gram and chickpea are considered, the soluble dietary fiber $(0.43 \%, 0.4 \%)$, insoluble dietary fiber $(8.8 \%, 7.2 \%)$ and total dietary fiber $(9.2 \%, 7.6 \%)$ respectively. The mean glycemic response to boiled green gram and boiled chickpea were $19.7( \pm 4.36)$ and $20.8( \pm 3.9) \mathrm{mg}$ dl-1 respectively. Boiled green gram contained more soluble dietary fibers, insoluble dietary fiber and total dietary fiber than chickpea. Due to higher fiber content of boiled green gram and chickpea the glycemic response was delayed ad were less $[15,18]$. Boiled green gram and chickpea are low GI diets and are good for diabetic and coronary heart disease patients.

\section{Glycemic Index values of some bakery products [22]}

The glycemic index of the bakery products such as bread, normal bun, butter cake, hard bun, and rusk available in Jaffna was determined (Table 1).

\begin{tabular}{|l|l|}
\hline Foods & GI \\
\hline Low Glycemic Index Foods; (GI<55) & 43.74 \\
\hline Pittu (Rice flour: Wheat flour=2:1) & 50.01 \\
\hline String hopper (Rice flour: Wheat flour=2:1) & 31.43 \\
\hline Greengram & 33.27 \\
\hline Chickpea & 34.80 \\
\hline Papaya & 54.45 \\
\hline 'Kathali' plantain & 50.43 \\
\hline 'Kappal' plantain & 48.47 \\
\hline 'Itharai' plantain & 50.30 \\
\hline Hard bun & 52.78 \\
\hline Rusk & \\
\hline Intermediate Glycemic Index Foods (GI 55-70) & \\
\hline
\end{tabular}




\begin{tabular}{|l|l|}
\hline 'Idly' & 58.37 \\
\hline 'Thosai' & 63.57 \\
\hline White rice & 66.61 \\
\hline Red rice & 60.24 \\
\hline Parboiled rice & 55.97 \\
\hline Semi boiled potato & 65.16 \\
\hline Jack fruit & 65.16 \\
\hline Wheat flour bread & 68.57 \\
\hline Buns & 67.30 \\
\hline Butter cake & 64.72 \\
\hline High Glycemic Index Foods (GIP70) & \\
\hline Boiled cassava & 78.67 \\
\hline
\end{tabular}

Table 1: Glycemic index of Northern Sri Lankan meals.

When fiber contents of the bread and normal bun were considered, bread contained less soluble dietary fiber $(0.5 \%)$ and more insoluble dietary $(2.73 \%)$ and total dietary fibers $(3.23 \%)$, than the normal bun (0.56, 2.43 and $2.99 \%$ respectively). The SDF, IDF and TDF of wheat bread and normal bun did not show much difference. Even though, bread contains higher IDF, the mean glycemic response to bread is higher $\left(43.0 \pm 2.32 \mathrm{gL}^{-1}\right)$ than the normal bun $\left(42.2 \pm 3.15 \mathrm{gL}^{-1}\right)$. It could be due to the less amount of SDF in wheat bread.

When fiber contents of the normal bun and hard bun were considered, hard bun contained more soluble dietary fiber $(0.76 \%)$, insoluble dietary fiber $(2.99 \%)$ and total dietary fibers $(3.75 \%)$, than the normal bun $(0.56,2.43$ and $2.99 \%$ respectively). The mean glycemic response to normal bun $\left(42.2 \pm 3.15 \mathrm{gL}^{-1}\right)$ is higher than the hard bun $\left(33.1 \pm 3.39 \mathrm{gL}^{-1}\right)$. This could be due to the effects of SDF, IDF and TDF in these buns.

The soluble dietary fiber $(0.6 \%)$, insoluble dietary fiber $(2.57 \%)$ and total dietary fibers $(3.17 \%)$, of butter cake were higher than the bread and normal bun. The mean glycemic response to butter cake was 40.5 $\left( \pm 4.03 \mathrm{gL}^{-1}\right)$ and this was lower than those of bread and normal bun and this could be due to the higher dietary fiber content while the fat content did not influence.

Rusk contained more soluble dietary fiber $(0.87 \%)$, insoluble dietary fiber $(3.18 \%)$ and total dietary fiber $(4.05 \%)$ than other bakery products. Among all the bakery products, rusk gave the lowest glycemic response $\left(31.1 \pm 3.03 \mathrm{mgdL}^{-1}\right)$. Here the soluble dietary fiber highly influenced the glycemic response than insoluble dietary fiber. The hard bun and rusk are lower GI diets (GI values <55\%). Bread, normal bun and butter cake are medium GI diets (GI values between $55-70 \%)$.

\section{Glycemic Index values of some fruits [23]}

This glycemic index (GI) values of fruits such as 'Kathali' (Yellow plantain), 'Kappal' (Golden plantain), and 'Itharai' (Green plantain) varieties of plantains, jackfruit and papaya were studied. The mean GI values of the 'Kathali', 'Kappal', 'Itharai' varieties of plantains, jack fruit and papaya were $54.45( \pm 9.26), 50.43( \pm 5.79), 48.47( \pm 10.13)$ $65.36( \pm 8.00)$ and $34.80( \pm 12.78) \%$ respectively (Table 1$)$. The three varieties of plantains and papaya were low GI fruits, and jackfruit was found to be an intermediate GI fruit. The presence of dietary fiber, esp. soluble fiber, reduces the glycemic response and glycemic index of foods. Thus among the different types of plantain varieties, ripped 'ithari' is best followed by kappal. However among the fruits, papya is the best followed by 'Ithari' variety of plantain [23].

\section{Effect of side dishes on Glycemic Index [24-31]}

The mean GI values of parboiled rice ('Mottaikarupan'), 'kurakkan pittu' (Eleucine coracana) and 'atta pittu' (whole wheat grain flour) either with green leaf curry (Amaranthus) or gravy (soya meat) or green leaf curry and gravy were determined (Table 2) [24-27]. The mean GI values of 'Thosai' /'Idly' either with 'sambol' or 'sambol' and plantain ('itharai') or 'sampar' or 'sampar' and plantain or 'sambol' and 'sampar' or 'sambol', 'sampar' and plantain were also determined (Table 2) [28-31].

The GI of parboiled rice or 'kurakkan pittu' or 'atta pittu' with green leaf curry differed significantly $(\mathrm{p}<0.05)$ from other combined foods. The GI of parboiled rice or 'kurakkan pittu' or 'atta pittu' with gravy or green leaf curry and gravy did not differ significantly $(\mathrm{p}>0.05)$ among them. 'Kurakkan pittu' is inferior to 'atta pittu' and parboiled rice (24). Including curries to basic foods altered the GI. Therefore, when dietary advice is given to diabetic patients, not only the basic foods, but also the curries to be consumed have to be considered. From the findings it could be concluded that among the starch sources 'atta flour' pittu was the best followed by parboiled rice [24,25]. Even though we have had believed that 'kurakan' and its flour are good starch based diets for diabetics and CVD patients, and obese and overweight persons. The results indicated that the foods made out of 'kurakan flour should not be recommended for diabetics [24].

The GI values were decreased when the foods were consumed with 'sambol' $[28,29]$. Addition of 'Itharai' variety of plantain to above basic foods was significantly decreased Glycemic index of each mixed meals $(\mathrm{P}<0.05)[30]$. This was due high fiber content of plantain (TDF-3.7\%, 
Page 4 of 6

SDF-0.7\%, IDF-2.9\%). An increase in the fiber content of food can delay the glycemic response [24,28,30,31]. Fiber delays the digestion of starch in the stomach, transition time of the stomach contents to the duodenum, delay the diffusion of different saccharides in the duodenum, delay the hydrolysis of polysaccharides in the duodenum and delay the absorption of monosaccharides through the microvillai of the epithelial cells of the jejunum and the upper part of the ileum. Total dietary fiber content has a significant negative correlation with GI.
The composition of the food or meal will influence the blood glucose response. Further foods within the same classification can have different glycemic indices. Furthermore processing of the food influences the GI. During cooking gelatinization of starch takes place, the cell walls are ruptured and the starch molecules are released. Therefore structural integrity of cell wall and starch granules also determine the glycemic index. Thus, when consuming the basic foods with different slide dishes, the GI values would be altered.

\begin{tabular}{|c|c|c|}
\hline \multicolumn{2}{|l|}{ Foods } & \multirow{3}{*}{$\begin{array}{l}\text { Glycemic Index } \\
47.47\end{array}$} \\
\hline Main food items & Side dishes & \\
\hline \multirow[t]{3}{*}{ Parboiled Rice } & Green leave curry & \\
\hline & Soya meat gravy & 56.30 \\
\hline & Green leave curry+Soya meat gravy & 54.67 \\
\hline \multirow[t]{3}{*}{ ‘Kurakkan’ Pittu } & Green leave curry & 57.51 \\
\hline & Soya meat gravy & 63.25 \\
\hline & Green leave curry+Soya meat gravy & 50.25 \\
\hline \multirow[t]{3}{*}{ 'Atta' Pittu } & Green leave curry & 44.40 \\
\hline & Soya meat gravy & 50.80 \\
\hline & Green leave curry+Soya meat gravy & 46.28 \\
\hline \multirow[t]{6}{*}{ ‘Thosai' } & Sambol & 67.93 \\
\hline & Sambol+'Itharai'plantain & 60.17 \\
\hline & Sambar & 71.90 \\
\hline & Sambar+'Itharai'plantain & 68.59 \\
\hline & Sambol+Sambar & 65.63 \\
\hline & Sambol+Sambar+'Itharai'plantain & 63.0 \\
\hline \multirow[t]{6}{*}{ ‘Idly’ } & Sambol & 56.85 \\
\hline & Sambol+'Itharai'plantain & 51.10 \\
\hline & Sambar & 70.32 \\
\hline & Sambar+'Itharai'plantain & 67.45 \\
\hline & Sambol+Sambar & 63.09 \\
\hline & Sambol+Sambar+'Itharai'plantain & 61.30 \\
\hline
\end{tabular}

Table 2: Glycemic Index values of mixed meals in Northern Sri Lanka.

\section{Conclusions}

'Pittu', 'string hopper', green gram and chick pea, hard bun, rusk, three varieties of plantains and papaya are lower GI diets (GI values $<55 \%$ ). White rice, brown rice, parboiled rice, bread, normal bun, butter cake and jack fruit are medium GI diets (GI values between $55-70 \%)$. Cassava is high glycemic index diet (GI value $>70 \%$ ).

Parboiled rice either with green leaf curry or green leaf curry and gravy, 'atta pittu' either with green leaf curry or gravy, or green leaf curry and gravy are lower GI diets (GI values $<55 \%$ ). Parboiled rice with gravy, 'kurakkan pittu' either with green leaf curry or gravy or green leaf curry and gravy are medium GI diets (GI values between 55 to $70 \%)$.

'Thosai' either with 'sambol' or 'sambol' and plantain or 'sampar' and plantain or 'sambol' and 'sampar' or 'sambol', 'sampar' and plantain are medium GI foods (the GI values between 55 to $70 \%$ ). The 'Thosai' either with 'sampar' is high GI food (the GI values are more than $70 \%)$.

'Idly' with 'sambol' and plantain ('Itharai') is lower GI food. The 'Idly' either with 'sambol' or 'sampar' and plantain ('Itharai') or 
Page 5 of 6

'sambol' and 'sampar' or 'sambol', 'sampar' and plantain ('Itharai') are medium GI foods. The 'Idly' with 'sampar' are high GI foods.

Low glycemic index diets $(\mathrm{GI}<55 \%)$ are advisable for patients with diabetes and coronary heart disease 'Atta pittu' is the best choice for them followed by parboiled rice. Even though 'kurakkan pittu' was thought to be a good meal for these patients, it is inferior to 'atta pittu' and parboiled rice. Consumption of soluble fiber rich diets such as green leaf curry or 'Itharai' variety of plantain with main meals significantly reduces the rise in blood sugar level. Therefore, when dietary advices are given to diabetic patients, not only the basic foods have to be considered but also the slide dishes to be consumed. However recommendation of the foods should be made after analyzing the glycemic index, glycemic load and energy contents of the foods.

Further studies have to be carried out on the prediabetes and diabetes.

\section{Acknowledgements}

First and foremost, I wish to express my deep appreciation to my supervisor, Prof. (MS) V. Arasaratnam, Senior Professor, Department of Biochemistry, Faculty of Medicine, University of Jaffna for her guidance and continued supervision extended during the entire progress of my research period. I am grateful to my co-supervisor, Dr. S. Balakumar, Head, Department of Biochemistry, Faculty of Medicine, and University of Jaffna for his advice and for providing the facilities to carry out my research project successfully. My gratitude and sincere thanks to Dr. T. Peranantharajah, Consultant Physician, Jaffna Teaching Hospital for giving me valuable advices and encouragement to carry out my research project successfully. I would like to express my sincere thanks to Miss. S. Subajini, Assistant Lecturer, Department of Chemistry, Faculty of Agriculture, University of Jaffna, for her help in doing statistical analysis.

I am indebted with my deep sense to Mr. K. Thayananthan, Mr. N. Nithiyanantharajah, Mrs.K.Sritharan, Mrs. K. Nithiyanantharajah, Mr. T. Santhiramoorthy, Mr.M.Sutharsan,Mr. V. Jeyabalasundaram, Mr. S. Palanithurai and Mr. P. Kirupanantharajah for their help and cooperation. I offer my heartfelt thanks to the students of the Faculty of Medicine, University of Jaffna, who volunteered for this study. I also extend my sincere thanks to IRQUE medical study programme, University of Jaffna, Diagnostic Vision, George Steuart Agencies (PVT) LTD for financial assistances to carry out my research project successfully. I would like to thank my parents, brother, sister and my friends for their understanding and constant encouragement given to me. Last but not least, I thank to all who helped me and have not even been mentioned.

\section{References}

1. Joint FAO/WHO Expert Consultation (1997) Carbohydrates in Human Nutrition. FAO Food and Nutrition. Rome: 66.

2. Anderson GH (1997) Sugars and health. Nutrition Research 17: 1485-1498.

3. Brouns F, Bjorck I, Frayn KN, Gibbs AL, Lang V, et al. (2005) Glycaemic index methodology. Nutr Res Rev 18: 145-171.

4. Wolever TM, Bolognesi C (1996) Source and amount of carbohydrate affect postprandial glucose and insulin in normal subjects. J Nutr 126: 2798-2806.

5. http://www.mendosa.com/gi:html.
6. Brand-Miller JC, Holt SH, Pawlak DB, McMillan J (2002) Glycemic index and obesity. American Journal Clinical Nutrition 76: 281S-285S.

7. Srinivasan SR, Bao W, Wattigney WA, Berenson GS (1996) Adolescent overweight is associated with adult overweight and related multiple cardiovascular risk factors: the Bogalusa Heart Study. Metabolism 45: 235-240.

8. Heacock PM, Hertzler SR, Williams JA, Wolf BW (2005) Effects of a medical food containing an herbal alpha-glucosidase inhibitor on postprandial glycemia and insulinemia in healthy adults. J Am Diet Assoc 105: 65-71.

9. Giacco R, Parillo M, Rivellese AA, Lasorella G, Giacco A, et al. (2000) Long-term dietary treatment with increased amounts of fiber-rich lowglycemic index natural foods improves blood glucose control and reduces the number of hypoglycemic events in type 1 diabetic patients. Diabetes Care 23: 1461-1466.

10. Galgani J, Agurirre C, Diaz E (2006) Acute effect of meal glycemic and glycemic load on blood glouse and insulin response in humans. Nutr J. 5: 22.

11. Pearson D (1976) The Chemical analysis of foods. (7thedn.). Edinburgh, London, Churchill. Living stone.

12. http://www.megazyme .com/booklets/KTDFR.pdf.

13. Wolever TM, Jenkins DJ, Jenkins AL, Josse RG (1991) The glycemic index: methodology and clinical implications. Am J Clin Nutr 54: 846-854.

14. Foster-Powell K, Holt SH, Brand-Miller JC (2002) International table of glycemic index and glycemic load values: 2002. Am J Clin Nutr 76: 5-56.

15. Pirasath S, Thayananthan K, Balakumar S, Arasaratnam V (2012) Effect of soluble fiber on glycemic index. Galle Medical Journal 17: 23-31.

16. Pirasath S, Balakumar S, Thayaananthan K Arasaratnam V (2011) Glycemic Index values of locally available foods in Jaffna. Ceylon Medical Journal 56: 36 .

17. Pirasath S, Balakumar S, Thayaananthan K ,Arasaratnam V (2011) Glycaemic Index values of locally available foods in Jaffna. Proceedings of the 124th Annual Scientific Sessions of Sri Lanka Medical Association: 36.

18. Pirasath S, Balakumar S, Arasaratnam V (2011) Do traditional foods help to decrease the glycaemic index? Proceedings of the 39th Annual Scientific Sessions of Batticalo Medical Association, 32-33.

19. Pirasath S, Thayaananthan K, Balakumar S, Arasaratnam V (2011) Glycaemic indices of selected food items from Jaffna. Proceedings of the 44th Annual Scientific Sessions of Ceylon College of Physicians: 61-62.

20. Pirasath S, Balakumar S, Thayaananthan K, Arasaratnam V (2011) Soluble fiber rich diets decrease the glycaemic indices. Public Health Forum, Proceedings of the 15th Annual Scientific Sessions of College of Community Physicians of Sri Lanka: 24.

21. Pirasath S, Balakumar S, Thayaananthan K, Arasaratnam V (2011) Do traditional foods help to decrease the glycaemic index? Evidence2011, Public Healthcare Form, British Medical Journal Group, British Medical Association and Evidenced Based Medicine, Oxford University, UK: 160.

22. Pirasath S, Thayananthan K, Balakumar S, Arasaratnam V (2011) Bakery products and their glycemic indicies in Jaffna. Jaffna Medical Journal 27: $38-43$.

23. Selladurai Pirasath, Kulasingam Thayananthan, Sandrasekarampillai Balakumar, Vasanthy Arasaratnam (2012) Glycemic Index values of some Jaffna fruits. International Journal of Functional Foods in Health and Disease 2: 25-34.

24. Pirasath S, Thayaananthan K, Balakumar S, Arasaratnam V (2010) Effect of dietary curries on the glycaemic index. Ceylon Med J 55: 118-122.

25. Pirasath S, Thayaananthan K, Balakumar S, Sivarajah, N, Arasaratnam V (2008) Including curries to basic foods alter the glycaemic indices. Proceedings of the Annual Research Symposium, University of Colombo: 64-65.

26. Pirasath $\mathrm{S}$, Thayaananthan $\mathrm{K}$, Balakumar S, Sivarajah N, Arasaratnam V (2009) Including curries to basic foods alter the glycaemic indices. 
Citation: Pirasath S, Balakumar B, Arasaratnam V (2015) Glycaemic Index of Sri Lankan Meals. J Blood Disorders Transf 6: 254. doi: 10.4172/2155-9864.1000254

Page 6 of 6

Proceedings of the 37th Annual Scientific Sessions of Batticalo Medical Association, 27.

27. Pirasath $\mathrm{S}$, Thayaananthan $\mathrm{K}$, Balakumar S, Sivarajah N, Arasaratnam V (2009) Glycaemic Index is altered with combined food items. Proceedings of the 42nd Annual Scientific Session, Ceylon College of Physicians, 50.

28. Pirasath S, Thayananthan K, Balakumar S, Arasaratnam V (2013) Including side dishes to traditional main meals alter the glycemic index. Journal of Endocrinology, Diabetes and Metabolism 3: 12-18.

29. Pirasath S, Thayananthan, Balakumar S, Arasaratnam V (2014) Thosai mixed side dishes altered the Glycemic Index. Batticaloa Medical Journal 6: $24-28$.
30. Pirasath S, Balakumar S, Arasaratnam V (2012) Effect of banana on glycaemic index. 10th International Conference on functional foods and bioactive compounds in health and disease, University of California, USA, 83-85.

31. Pirasath S, Balakumar S, Thayaananthan K, Arasaratnam V (2011) Glycaemic index is altered with the mixed meals. Annual Scientific Session, Jaffna Medical Association, 16. 